patients with acute myocardial infarction. Chest 1987;92:721-7.

13 Zion MM, Balkin J, Rosenmann D, Goldbourt U, et al. Use of pulmonary artery catheters in patients with acute myocardial infarction. Analysis of experience in 5,841 patients in the SPRINT Registry. SPRINT Study Group. Chest 1990;98:1331-5.

14 Rhodes A, Cusack RJ, Newman PJ, Grounds RM, Bennett ED. A randomised controlled trial of the pulmonary artery catheter in critically ill patients. Intensive Care Med (in press).

15 Boyd O, Grounds RM, Bennett ED. A randomized clinical trial of the effect of deliberate perioperative increase of oxygen delivery on mortality in high-risk surgical patients. JAMA 1993;270:2699-707.

16 Hayes MA, Timmins AC, Yau EH, Palazzo $\mathrm{M}$, et al. Elevation of systemic oxygen delivery in the treatment of critically ill patients. N Engl J Med 1994;330:1717-22.

17 Rapoport J, Teres D, Steingrub J, Higgins T, et al. Patient characteristics and ICU organizational factors that influence frequency of pulmonary artery catheterization. JAMA 2000;283:2559-67.

\section{The acute respiratory}

distress syndrome:

recent advances in

\section{ventilation}

Darryl Johnston FRCA,

Specialist Registrar in Anaesthesia

Stephen Brett MD FRCA,

Consultant in Intensive Care Medicine

Department of Anaesthesia and Intensive

Care Medicine, Hammersmith Hospital,

London

Clin Med JRCPL 2002;2:104-8

\section{Definition of the acute respiratory distress syndrome}

The acute respiratory distress syndrome (ARDS) is a diffuse pulmonary parenchymal injury associated with non-cardiogenic pulmonary oedema, resulting in severe respiratory distress and hypoxic respiratory failure. It is characterised by a triad of refractory hypoxaemia, diffuse lung infiltrates on chest radiograph and poor lung compliance. ARDS was described by Ashbaugh and colleagues in $1967^{1}$ and in subsequent studies, the diagnosis being made on clinical grounds. The current accepted definition was set out by an American-European Consensus Conference in $1994^{2}$. This defined two levels of severity in acute lung injury, based on a hypoxaemia score, ARDS being the extreme end of a spectrum of generic acute lung injury:

- acute lung injury:

$\mathrm{PaO}_{2} / \mathrm{FiO}_{2}<40 \mathrm{kPa}$;

ARDS:

$\mathrm{PaO}_{2} / \mathrm{FiO}_{2}<27 \mathrm{kPa}$

associated with:

- bilateral infiltrates on chest radiograph

- absence of cardiac failure

- acute onset of an appropriate condition.

ARDS is now regarded as the pulmonary manifestation of a systemic inflammatory response and can result from either a local (aspiration, pneumonia, smoke inhalation) or systemic insult (sepsis, trauma, pancreatitis, intravascular coagulation). Surprisingly, 95\% of deaths from ARDS are not due to hypoxaemia but to sepsis or multi-organ failure $^{3}$. The prognosis is variable and depends on the underlying diagnosis, sepsis having a higher mortality. Recent studies from referral centres report an overall mortality rate of around $40 \%{ }^{4,5}$.

\section{Pathology}

The characteristic pathology of ARDS is of diffuse alveolar damage resulting in loss of integrity of the capillary-alveolar barrier, with increasing permeability and subsequent proteinaceous oedema. Surfactant dysfunction occurs, leading to loss of alveolar stability and atelectasis. This results in intrapulmonary shunting and refractory hypoxaemia ${ }^{6}$.

\title{
GLOSSARY OF TERMS
}

PEEP: $\quad$ positive end expiratory pressure - a ventilator mechanism which prevents alveolar pressure declining to atmospheric pressure at end expiration. It increases functional residual capacity and can maintain alveolar opening and stability.

APACHE II: acute physiology and chronic health evaluation score - a regression-derived scoring system used as an index of illness severity calculated on day one of intensive care unit stay. It produces a risk of death, but this must be used with extreme caution and not for individual patient management.

$\mathrm{FiO}_{2}: \quad$ the inspired oxygen concentration, expressed as a fraction or a percentage.

$\mathrm{PaO}_{2}$ : the partial pressure of oxygen in arterial blood, expressed as kiloPascals $(\mathrm{kPa})$ or $\mathrm{mmHg}$. 


\section{Treatment}

To date, there are no specific therapeutic interventions. The priorities are thus to identify and treat the precipitating cause and to intervene with multisystem support, if appropriate.

\section{The mechanics of ventilation}

Much recent research has concentrated on the mechanics of ventilation and on how best to optimise this in the context of injured lungs. This has included plotting the static pressure-volume curves of the respiratory system. The resulting graphs often demonstrate two inflection points during inspiration:

- the lower inflection point, which is thought to represent the opening of collapsed alveoli

- the upper inflection (deflection) point which represents a point above which overdistension occurs, and after which small increments in tidal volume cause large increases in pressure (see, for example, Fig $1^{7}$ ).

Computed tomography (CT) studies have demonstrated that PEEP can prevent collapse of the alveoli at end expiration $^{8}$, and confirm that inflation above the upper inflection point does not aid lung recruitment but overdistends the lung $^{7}$. Overdistension has been implicated in lung damage evident at follow-up 9 . Thus, there may be a theoretical advantage to ventilating between these two inflection points.

\section{Laboratory studies}

This hypothesis is supported by laboratory studies. For example, in a recent study, rabbit lungs were instilled with Pseudomonas aeruginosa to induce lung injury, and subsequently ventilated with tidal volumes of either $6 \mathrm{ml} / \mathrm{kg}$ or $15 \mathrm{ml} / \mathrm{kg}^{10}$. Radiolabelled albumin was used to measure the alveolar permeability. Significant increases in permeability were demonstrated for the large tidal volume group. Other animal studies have shown that tidal closing and opening of alveoli is deleterious, and that an adequate level of PEEP, preventing so-called tidal recruitment, is protective ${ }^{11}$.

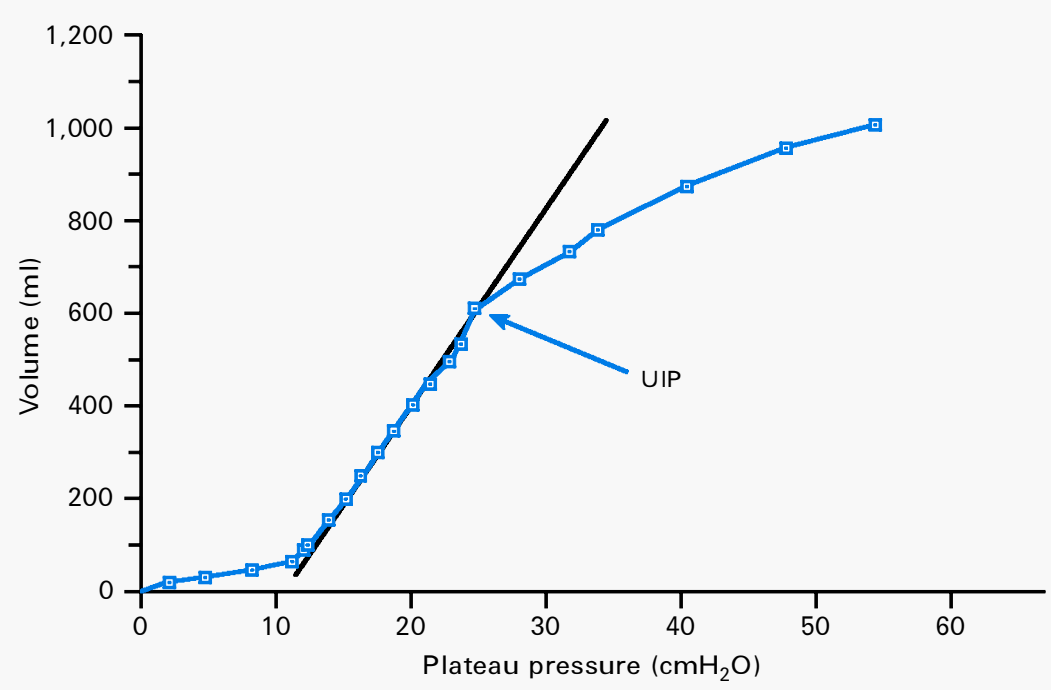

Fig 1. Representative example of a pressure-volume curve of the respiratory system obtained in a patient. The lower inflection point is used to determine the level of applied PEEP. The first upper point above which the curve consistently deviates from the linear part of the curve at high lung volume is called the upper inflection point (UIP) and is used to set the reduced tidal volume. Reproduced with permission from Dambrosio $M$, Roupie E, Mollett JJ, Anglade MC, et al. Effects of positive end-expiratory pressure and different tidal volumes on alveolar recruitment and hyperinflation. Anesthesiology 1997;87(3):497. Lippincott, Williams and Wilkins.

\section{Clinical studies}

Clinical studies from New Zealand ${ }^{12}$ showed limiting ventilatory pressures had a beneficial effect. This group reduced tidal volumes and disregarded hypercapnia, subsequently showing a significant reduction in hospital mortality compared with that predicted by APACHE II scores (16\% vs $39.6 \%$ ). However, although important, this was not a prospective or concurrently controlled study and involved a relatively small number of patients (50). Since then, a number of multicentre trials have produced somewhat conflicting evidence. An early example was a study of patients with severe $\mathrm{ARDS}^{13}$, in which two well matched groups were ventilated with target tidal volumes of $7 \mathrm{ml} / \mathrm{kg}$ and $10 \mathrm{ml} / \mathrm{kg}$, with peak airway pressures limited to $25 \mathrm{cmH}_{2} \mathrm{O}$ and $31 \mathrm{cmH}_{2} \mathrm{O}$, respectively. No significant difference was demonstrated in 60-day mortality ( $46.6 \%$ vs $37.9 \%, p=0.38$ ), duration of ventilation (23.1 days vs 21.4 days, $p=0.85$ ), pneumothorax ( $14 \%$ vs $12 \%$, $p=0.78)$ or secondary organ failure $(41 \%$ vs $41 \%, p=1)$.
A further randomised controlled trial $^{14}$ of patients at risk of ARDS compared ventilation to $8 \mathrm{ml} / \mathrm{kg}$ and $10-15 \mathrm{ml} / \mathrm{kg}$ target tidal volumes. Peak inspiratory pressures were maintained at less than $30 \mathrm{cmH}_{2} \mathrm{O}$ and less than $50 \mathrm{cmH}_{2} \mathrm{O}$ for the low volume and control groups, respectively. Hypercapnia was permitted. Mortality was unchanged ( $50 \%$ in the low tidal volume group vs $47 \%$ in the controls). The incidence of barotrauma, highest multiple organ dysfunction score and the number of organ failures was similar in both groups. However, in the low ventilation group more patients required paralytic agents and a greater number required renal support. The significance of these observations is unclear.

In the same year another trial comparing 'protective' low tidal volume strategy with conventional ventilation showed a significant difference in outcome $^{15}$. This time a larger difference in target tidal volumes $(6 \mathrm{ml} / \mathrm{kg}$ vs $12 \mathrm{ml} / \mathrm{kg}$ ) was robustly enforced. In the protective ventilation group a PEEP level above the lower inflection point was used and inspiratory pressures were maintained 


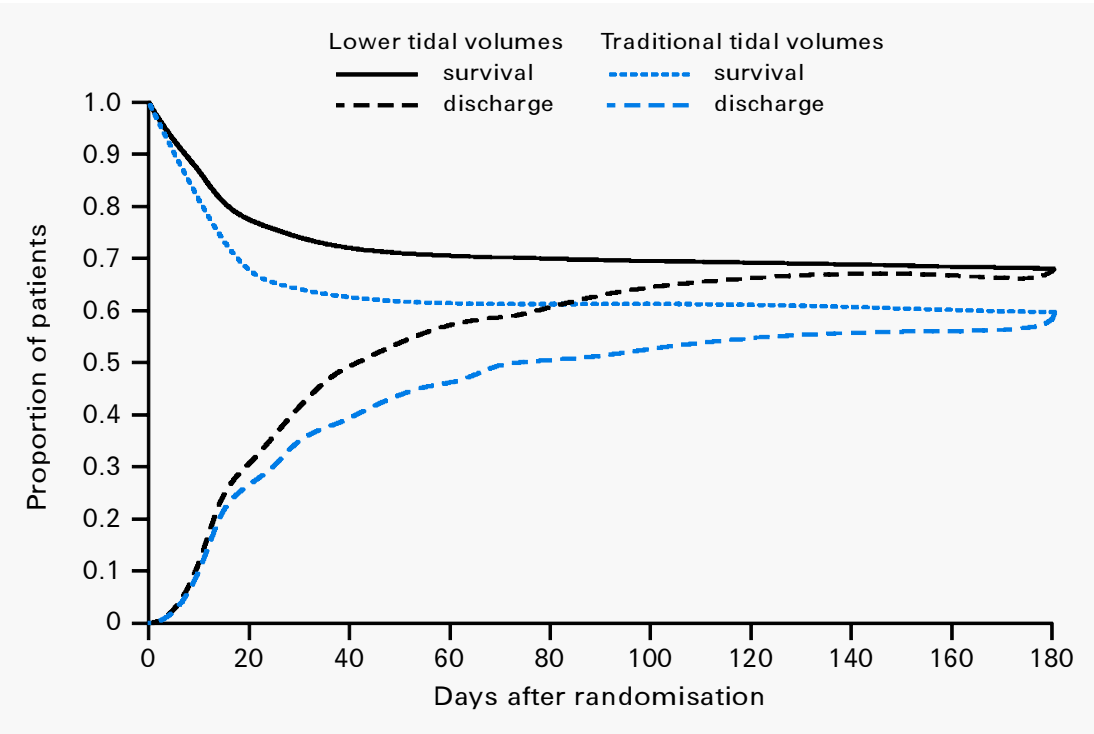

Fig 2. Probability of survival and of being discharged home and breathing without assistance during the first 180 days after randomisation in patients with acute lung injury and the acute respiratory distress syndrome. The status at 180 days or at the end of the study was known for all but nine patients. Data on these nine patients and on 22 additional patients who were hospitalised at the time of the fourth interim analysis were censored. From Ref 16, with permission. Copyright (c) 2000 Massachusetts Medical Society. All rights reserved.

below $20 \mathrm{cmH}_{2} \mathrm{O}$. This reduced 28-day mortality from $71 \%$ to $38 \%(p<0.001)$. Additionally, successful weaning improved from $29 \%$ to $66 \%$ ( $p=0.005)$ and barotrauma fell from $42 \%$ to $7 \%$ $(p=0.02)$. Concern has been expressed about the high mortality in the control group and a surprisingly high incidence of accidental extubation.

The most significant multicentre trial examining the low tidal volume hypothesis was published in $2000^{16}$. This was the ARDS Network study supported by the
US National Institutes of Health. Patients were randomised into two groups:

- group 1: $6 \mathrm{ml} / \mathrm{kg}$ target tidal volume and airway pressure limited to less than $30 \mathrm{cmH}_{2} \mathrm{O}$

- group 2: $12 \mathrm{ml} / \mathrm{kg}$ tidal volume and airway pressure of up to $50 \mathrm{cmH}_{2} \mathrm{O}$.

The trial was highly protocol driven to reduce unavoidable intercentre variability in non-ventilatory aspects of care, bicarbonate treatment of severe acidosis was permitted, and rapid ventilatory

\section{Key Points}

The mortality for patients with acute respiratory distress syndrome (ARDS) is now reported to be around $40 \%$ in recent series

The strategy adopted for mechanical ventilation of the lungs of patients with ARDS has been shown to affect mortality

An approach to ventilatory support based on small tidal volumes appears to be beneficial

There is experimental evidence that suboptimal ventilatory strategies can produce or contribute to a systemic inflammatory response

KEY WORDS: CPD, acute lung injury, acute respiratory distress syndrome, inflammation, mechanical ventilation, respiratory failure rates were used to moderate the inevitable hypercapnia. The trial was stopped after the enrolment of 861 patients (Fig 2) because mortality was significantly lower in the lower tidal volume group $(31 \%$ vs $39.8 \%$, $p=0.007)$.

\section{Why did the studies give conflicting} results?

The latter two trials differed from earlier studies in that they represented a very robust test of the hypothesis with actual tidal volumes and pressures delivered substantially different between the two groups studied. In addition, the use of bicarbonate to correct severe acidosis may have been important. The recruited populations differed subtly, and the strategies concerning use of PEEP also varied. The ARDS Network study is currently regarded as the final arbiter, even though the possibility cannot be discounted that the control group strategy was harmful rather than the protective ventilation strategy being beneficial However, the control group mortality was in line with current accepted levels and the illness severity was substantial.

\section{Effect of ventilation strategy on outcome}

Why should the pattern of ventilation affect outcome? We have seen from the animal laboratory studies that tidal recruitment is harmful. In the clinical arena, profiles of lung mechanics have been investigated using CT. Initial studies demonstrated that lung densities were predominantly distributed in dependent zones ${ }^{17}$. By repositioning the patient in the prone position, there was movement of the lung densities from the ventral to the dorsal aspect ${ }^{18}$. Using a similar imaging approach, PEEP was found to increase the amount of normally inflated lung by recruitment of previously collapsed alveoli ${ }^{19}$ and to a significant extent prevent end expiratory de-recruitment. Gross ventilator trauma was examined by Weg and colleagues ${ }^{20}$ who failed to find a relationship between this and outcome in a retrospective review of over 700 cases. 
In a parallel line of research, the impact of ventilatory strategy on the release of inflammatory mediators in both the local environment and the systemic circulation has been examined. In a rat model of hydrochloric acidinduced lung injury ${ }^{21}$, animals ventilated with high volumes had increased concentrations of inflammatory cytokines (tumour necrosis factor (TNF)- $\boldsymbol{\alpha}$ and macrophage inflammatory protein-2) in the lung fluid and plasma. A subsequent study using a rabbit model of direct endotoxin instillation examined the ability of the lung to compartmentalise endotoxin $^{22}$. Animals were ventilated with either high or low tidal volumes, or high or low levels of PEEP in a four-group design. The most injurious strategy (high volume, zero PEEP) produced a high level of plasma endotoxin and TNF- $\alpha$.

\section{Can the results be translated into the intensive care unit?}

A randomised controlled trial ${ }^{23}$ examined the possibility of translating the findings into clinical practice in 44 patients with ARDS. Pressure-volume curves were obtained and bronchoalveolar lavage and blood samples taken. The patients were randomised into either a control or protective ventilation group. The control groups were ventilated to achieve a normal arterial carbon dioxide. The protective group had a tidal volume and PEEP based on their individual pressure-volume curves. Measurements and sampling were repeated at 36 hours. Although not conclusive, overall the samples from the control groups showed an increase in inflammatory cytokines and lavage neutrophil counts, whereas there was a decrease in the protective ventilation group. This supports the hypothesis that ventilation strategy affects inflammatory processes.

If 'conventional' tidal volume ventilation is harmful in acute lung injury, would ventilation with very small volume excursions be beneficial? Currently this is being investigated using high frequency oscillatory ventilation; the early reports are encouraging ${ }^{24}$. The importance of the ARDS Network study is difficult to overstate. It is the first study to show an unequivocal advantage of a particular ventilation strategy in a large multicentre randomised trial. Overall, these studies provide definite evidence to support the hypothesis that the use of low tidal volumes to ventilate is beneficial in the patient with severe ARDS.

\section{References}

1 Ashbaugh DG, Bigelow DB, Petty TL, Levine BE. Acute respiratory distress in adults. Lancet 1967;ii:319-23.

2 Bernard GR, Artigas A, Brigham KL, Carlet J, et al. The American-European Consensus Conference on ARDS. Definitions, mechanisms, relevant outcomes, and clinical trial coordination. Review. Am J Respir Crit Care Med 1994; 149:818-24.

3 Montgomery AB, Stager MA, Carrico CJ, Hudson LD. Causes of mortality in patients with the adult respiratory distress syndrome. Am Rev Respir Dis 1985;132:485-9.

4 Milberg JA, Davis DR, Steinberg KP, Hudson LD. Improved survival of patients with acute respiratory distress syndrome (ARDS): 1983-1993. JAMA 1995;273:306-9.

5 Abel SJ, Finney SJ, Brett SJ, Keogh BF, et al. Reduced mortality in association with the acute respiratory distress syndrome (ARDS). Thorax 1998;53:292-4.

6 Dantzker DR, Brook CJ, Dehart P, Lynch JP, Weg JG. Ventilation-perfusion distributions in the adult respiratory distress syndrome. Am Rev Respir Dis 1979;120:1039-52.

7 Dambrosio M, Roupie E, Mollett JJ, Anglade MC, et al. Effects of positive end-expiratory pressure and different tidal volumes on alveolar recruitment and hyperinflation. Anesthesiology 1997;87:495-503.

8 Gattinoni L, Pelosi P, Crotti S, Valenza F. Effects of positive end-expiratory pressure on regional distribution of tidal volume and recruitment in adult respiratory distress syndrome. Am J Respir Crit Care Med 1995;151:1807-14.

9 Finfer S, Rocker G. Alveolar overdistension is an important mechanism of persistent lung damage following severe protracted ARDS. Anaesth Intensive Care 1996;24:569-73.

10 Savel RH, Yao EC, Gropper MA. Protective effects of low tidal volume ventilation in a rabbit model of Pseudomonas aeruginosa-induced acute lung injury. Crit Care Med 2001;29:392-8.

11 Muscedere JG, Mullen JB, Gan K, Slutsky AS. Tidal ventilation at low airway pressures can augment lung injury. Am J Respir Crit Care Med 1994;149:1327-34.
12 Hickling KG, Henderson SJ, Jackson R. Low mortality associated with low volume pressure limited ventilation with permissive hypercapnia in severe adult respiratory distress syndrome. Intensive Care Med 1990; 16:372-7.

13 Brochard L, Roudot-Thoraval F, Roupie E, Delclaux C, et al. Tidal volume reduction for prevention of ventilator-induced lung injury in acute respiratory distress syndrome. The Multicenter Trial Group on Tidal Volume reduction in ARDS. Am J Respir Crit Care Med 1998;158:1831-8.

14 Stewart TE, Meade MO, Cook DJ, Granton JT, et al. Evaluation of a ventilation strategy to prevent barotrauma in patients at high risk for acute respiratory distress syndrome. Pressure- and Volume-Limited Ventilation Strategy Group. N Engl J Med 1998;338: 355-61.

15 Amato MB, Barbas CS, Medeiros DM Magaldi RB, et al. Effect of a protective-ventilation strategy on mortality in the acute respiratory distress syndrome. $\mathrm{N} \mathrm{Engl} \mathrm{J} \mathrm{Med}$ 1998;338:347-54.

16 Ventilation with lower tidal volumes as compared with traditional tidal volumes for acute lung injury and the acute respiratory distress syndrome. The Acute Respiratory Distress Syndrome Network. N Engl J Med 2000;342:1301-8.

17 Gattinoni L, Pesenti A, Torresin A, Baglioni $\mathrm{S}$, et al. Adult respiratory distress syndrome profiles by computed tomography. J Thorac Imaging 1986;1:25-30.

18 Gattinoni L, Pelosi P, Vitale G, Pesenti A, et al. Body position changes redistribute lung computed-tomographic density in patients with acute respiratory failure. Anesthesiology 1991;74:15-23.

19 Gattinoni L, Pesenti A, Bombino M, Baglioni S, et al. Relationships between lung computed tomographic density, gas exchange, and PEEP in acute respiratory failure. Anesthesiology 1988;69:824-32.

20 Weg JG, Anzueto A, Balk RA, Wiedemann $\mathrm{HP}$, et al. The relation of pneumothorax and other air leaks to mortality in the acute respiratory distress syndrome. $N$ Engl J Med 1998;338:341-6.

21 Chiumello D, Pristine G, Slutsky AS Mechanical ventilation affects local and systemic cytokines in an animal model of acute respiratory distress syndrome. Am J Respir Crit Care Med 1999;160:109-16.

22 Murphy DB, Cregg N, Tremblay L, Engelberts D, et al. Adverse ventilatory strategy causes pulmonary-to-systemic translocation of endotoxin. Am J Respir Crit Care Med 2001;162:27-33.

23 Ranieri VM, Suter PM, Tortorella C, De Tullio R, et al. Effect of mechanical ventilation on inflammatory mediators in patients with acute respiratory distress syndrome: a randomized controlled trial. JAMA 1999;282:54-61.

24 Mehta S, Lapinsky SE, Hallett DC, Merker 
D, et al. Prospective trial of high-frequency oscillation in adults with acute respiratory distress syndrome. Crit Care Med 2001;29: 1360-9.

\section{Management of acute renal failure on the}

\section{intensive care unit}

Tony M Rahman MRCP MA, Senior Trainee

David Treacher FRCP, Consultant Physician

Department of Intensive Care Medicine,

St Thomas' Hospital, London

Clin Med JRCPL 2002;2:108-13

Acute renal failure (ARF) complicates up to $5 \%$ of all hospital admissions, and as many as $35 \%$ of patients admitted to an intensive care unit (ICU) receive renal replacement therapy $(\mathrm{RRT})^{1}$. These figures will vary with the case mix of the unit, the threshold at which RRT is instituted and the definition of ARF used. The lack of a consensus definition of ARF remains a major problem in interpreting studies of its epidemiology, management and outcome. In ICU, ARF nearly always occurs as part of multiple organ failure (MOF) for which mortality exceeds $60 \%$, rising to over $90 \%$ if four or more organs fail. Early diagnosis and the appropriate monitoring and timing of intervention will prevent the fatal metabolic sequelae of ARF. This article reviews the causes and management of ARF in the ICU.

\section{Aetiology}

The causes of acute oliguria and ARF may be conveniently grouped into three categories: pre-renal, renal and postrenal $^{2}$. Post-renal failure, which results from obstruction at the level of the renal pelvices, ureters or bladder outflow tract, develops relatively rarely on ICU but may be part of the problem precipitating admission. ARF in the ICU is most commonly due to pre-renal factors, particularly systemic hypotension and intravascular volume depletion causing renal hypoperfusion, progressing to acute tubular necrosis (ATN) if appropriate treatment is delayed. Intrinsic or primary parenchymal renal disease refers to the insults directly affecting the tubules, glomeruli and the renal vasculature (Table 1).

\section{Presentation}

ARF in acutely ill patients is frequently asymptomatic. It presents with a rising blood urea and creatinine, with or without clinical or biochemical hyperkalaemia and acidaemia, and a reduced urine output. This pattern has frequently started to develop during the hours or days before admission to ICU; it is included in protocols used to identify 'patients at risk' and to 'trigger' earlier referral. Acute oliguria is defined as urine excretion of less than $400 \mathrm{ml} /$ day, but in patients on the ICU, who are invariably catheterised, production of less than 0.5 $\mathrm{ml} / \mathrm{kg}$ /hour for two successive hours should prompt review.

A blocked urinary catheter or the intense salt and water retention associated with critical illness may be the cause, but should not be assumed until all pre-renal factors (blood pressure, cardiac output, tissue hydration, intraabdominal pressure) have been assessed and appropriate treatment instituted. Markedly elevated intra-abdominal pressure $\left(>30 \mathrm{cmH}_{2} 0\right)$ may also cause renal ischaemia. This may result from fluid accumulation and bowel distension after laparotomy or from gross ascites. Urgent measures are required for the lifethreatening complications of ARF but not for urea and creatinine levels alone unless they are markedly raised (Box 1$)^{3}$.

\section{History, examination and investigation}

A history of renal disease is frequently not available from the patient, but relevant past medical history, including pre-existing renal dysfunction and recent drug history, should be sought from the family, general practitioner and hospital notes (Box 2). Clinical examination should specifically address the following questions:

1 What is the cause of the oliguria/ ARF?

2 Are the blood pressure and intra- 